\title{
Effect of ambient temperature on the puffing characteristics of single
}

\section{butanol-hexadecane droplet}

\author{
Yu Zhang, ${ }^{\mathrm{a}, \mathrm{b}}$, Ronghua Huang ${ }^{\mathrm{a}, \mathrm{b} *}$, Yuhan Huang, ${ }^{\mathrm{a}, \mathrm{b}}$, Sheng Huang ${ }^{\mathrm{a}, \mathrm{b}}$, Yinjie Ma ${ }^{\mathrm{a}, \mathrm{b}}$, Shijie Xu ${ }^{\mathrm{a}, \mathrm{b}}$, Pei Zhou ${ }^{\mathrm{a}, \mathrm{b}}$ \\ ${ }^{a}$ State Key Laboratory of Coal Combustion, Huazhong University of Science and Technology, Wuhan, 430074, China \\ ${ }^{b}$ School of Energy and Power Engineering, Huazhong University of Science and Technology, Wuhan, 430074, China
}

\begin{abstract}
Puffing characteristics of BUT50 (50\% n-butanol and 50\% n-hexadecane by mass) were investigated using the droplet suspension technology under 638, 688 and $738 \mathrm{~K}$. Experimental results showed that BUT50 underwent transient heating, fluctuation evaporation and equilibrium evaporation phases under all ambient temperatures. In the fluctuation evaporation phase, the fluctuation frequency of $738 \mathrm{~K}$ was higher than those of 638 and $688 \mathrm{~K}$ and the $\left(\mathrm{D}_{\max } / \mathrm{D}_{0}\right)^{2}$ of $738 \mathrm{~K}$ was lower than those of 638 and $688 \mathrm{~K}$. Easy bubble rupture led to high fluctuation frequency and low $\left(\mathrm{D}_{\max } / \mathrm{D}_{0}\right)^{2}$ at $738 \mathrm{~K}$. Three turning points could be found in the curve of transient temperature growth rate at 638 and $738 \mathrm{~K}$. Four characteristic droplet temperatures were analyzed, including droplet temperatures at the start $\left(\mathrm{T}_{1}\right)$ and end $\left(\mathrm{T}_{2}\right)$ of transient heating phase, at $\left(\mathrm{D}_{\max } / \mathrm{D}_{0}\right)^{2}\left(\mathrm{~T}_{3}\right)$ and at the end of total lifetime $\left(T_{4}\right) . T_{2}$ was slightly lower and $T_{3}$ was slightly higher than the boiling point of $n$-butanol. $T_{4}$ was lower than the boiling point of n-hexadecane. Furthermore, the transient heating duration $\left(\mathrm{t}_{\mathrm{TH}}\right)$, fluctuation evaporation duration $\left(\mathrm{t}_{\mathrm{FE}}\right)$ and total lifetime $\left(t_{\mathrm{TL}}\right)$ decreased with increasing ambient temperature. The reduction of $t_{\mathrm{FE}}$ played an important role in the decrease of $t_{\mathrm{TL}}$. The percentages of $\mathrm{t}_{\mathrm{TH}} / \mathrm{t}_{\mathrm{TL}}$ and $\mathrm{t}_{\mathrm{FE}} / \mathrm{t}_{\mathrm{TL}}$ were stable with increasing ambient temperature.
\end{abstract}

Keywords: Ambient temperature; Puffing characteristics; Single droplet; Experimental study; Butanol-hexadecane blend 


\section{Highlights:}

- $\quad$ Easy bubble rupture led to high fluctuation frequency and low $\left(\mathrm{D}_{\max } / \mathrm{D}_{0}\right)^{2}$ at $738 \mathrm{~K}$.

- $\quad$ Three turning points were found in the curve of transient temperature growth rate at 638 and $738 \mathrm{~K}$.

- $\mathrm{T}_{2}$ was slightly lower and $\mathrm{T}_{3}$ was slightly higher than the boiling point of $\mathrm{n}$-butanol.

- $\quad$ Reduction of $t_{\mathrm{FE}}$ played an important role in the decrease of $\mathrm{t}_{\mathrm{TL}}$.

- Percentages of $t_{\mathrm{TH}} / \mathrm{t}_{\mathrm{TL}}$ and $\mathrm{t}_{\mathrm{FE}} / \mathrm{t}_{\mathrm{TL}}$ were stable with increasing ambient temperature.

\section{Corresponding author:}

Ronghua Huang, PhD, Professor

Postal address: School of Energy and Power Engineering, Huazhong University of Science and Technology, 1037 Luoyu Road, Wuhan China, 430074

Email: rhhuang@hust.edu.cn

Telephone: $+86-27-87541518$

\section{Nomenclature}

\section{Variables}

$\mathrm{C}$

D

$\mathrm{k}$

$\mathrm{n}$

$\mathrm{P}$

$\mathrm{S}$

$\mathrm{t}$

$\Delta \mathrm{t}$

$\mathrm{T}$

u

$\mathrm{X}$

$\mathrm{X}$

Y

$\lambda$

$\tau$
Circumference, $[\mathrm{mm}]$

Droplet diameter, [mm]

Rate of bubble expansion, $\left[\mathrm{mm}^{2} / \mathrm{s}\right]$

Number of experimental samples, [-]

Images, [-]

Projected area, $\left[\mathrm{mm}^{2}\right]$

Duration, $\left[\mathrm{s} / \mathrm{mm}^{2}\right.$ ]

Interval time of temperature data, $\left[\mathrm{s} / \mathrm{mm}^{2}\right]$

Temperature, [K]

Uncertainty

Experimental value

Contribution ratio to lifetime reduction, [-]

Normalized characteristic duration, [-]

Temperature growth rate, $\left[\mathrm{K} \cdot \mathrm{mm}^{2} / \mathrm{s}\right]$

Moment, $\left[\mathrm{s} / \mathrm{mm}^{2}\right]$

\section{Subscripts}

0

Initial moment

$\mathrm{amb}$

A

Ambient

A-type standard uncertainty

bac

Back

bot

Bottom

B B-type standard uncertainty

c

Circumference equivalent

C

Combined standard uncertainty

fro

Front

FE Fluctuation evaporation

HT High temperature

LT Low temperature

top Top

tran Transient

TH Transient heating

TL Total lifetime 


\section{Introduction}

Many researches are carried out to improve dynamic, economic and emission performances of diesel engines, including combustion optimization $[1,2]$, renewable fuels $[3,4]$ and waste gas utilization $[5,6]$. Diesel is a kind of non-renewable fossil fuels. Its combustion is a major contributor of anthropogenic climate change and environmental pollution [1, 7]. Therefore, it is necessary to find renewable and environmentally friendly fuels. n-Butanol has higher energy density and is more miscible with diesel than methanol and ethanol [8]. The oxygen content in n-butanol can improve fuel-oxygen mixture to reduce soot emissions [9]. n-Butanol also has the potential to reduce $\mathrm{NO}_{\mathrm{X}}$ formation due to its high latent heat of vaporization [3, 10]. Therefore, n-butanol is an attractive renewable fuel for diesel engines. Table 1 shows the physical properties of n-butanol, n-hexadecane and diesel. n-Butanol can not be used as a neat fuel in a diesel engine because of its lower heating value $\left(3.31 \times 10^{7} \mathrm{~J} / \mathrm{kg}\right), \mathrm{lower}$ kinematic viscosity $\left(2.22 \times 10^{-6} \mathrm{~m}^{2} / \mathrm{s}\right)$, lower cetane number $(25)$ and higher auto-ignition temperature (658 $\left.\mathrm{K}\right)$ than diesel (heating value: $4.25 \times 10^{7} \mathrm{~J} / \mathrm{kg}$, kinematic viscosity: $2.70 \times 10^{-6} \mathrm{~m}^{2} / \mathrm{s}$, cetane number: $40-55$, auto-ignition temperature: $501 \mathrm{~K}$ ).

Table 1 Physical properties of n-butanol, n-hexadecane and diesel [3, 13, 22, 28, 29]

\begin{tabular}{|c|c|c|c|}
\hline Physical properties & n-Butanol & n-Hexadecane & Diesel \\
\hline Molecular formula & $\mathrm{C}_{4} \mathrm{H}_{9} \mathrm{OH}$ & $\mathrm{C}_{16} \mathrm{H}_{34}$ & $\mathrm{C}_{12}-\mathrm{C}_{25}$ \\
\hline Molecular weight & 74.12 & 226.44 & - \\
\hline Lower heating value, $[\mathrm{J} / \mathrm{kg}]$ & $3.31 \times 10^{7}$ & $4.42 \times 10^{7}$ & $4.25 \times 10^{7}$ \\
\hline Latent heat of vaporization, $[\mathrm{J} / \mathrm{kg}]$ & $5.85 \times 10^{5}$ & $2.74 \times 10^{5}$ & $2.50 \times 10^{5}$ \\
\hline Kinematic viscosity at $313 \mathrm{~K},\left[\mathrm{~m}^{2} / \mathrm{s}\right]$ & $2.22 \times 10^{-6}$ & $3.28 \times 10^{-6}$ & $2.70 \times 10^{-6}$ \\
\hline Oxygen content, [\%] & 21.6 & - & - \\
\hline Density at $293 \mathrm{~K},\left[\mathrm{~kg} / \mathrm{m}^{3}\right]$ & 810 & 770 & 830 \\
\hline Boiling point at 1 bar, $[\mathrm{K}]$ & 390 & 560 & $458-618$ \\
\hline Auto-ignition temperature, $[\mathrm{K}]$ & 658 & 483 & 501 \\
\hline Cetane number, [-] & 25 & 100 & $40-55$ \\
\hline
\end{tabular}

The addition of high n-butanol content into diesel can improve engine performance and emission characteristics $[2,7,11,12]$.

The combination between high n-butanol content and exhaust gas recirculation (EGR) could simultaneously reduce $\mathrm{NO}_{\mathrm{X}}$ and soot emissions [2]. ABE50 (the blend of 50\% ABE and 50\% diesel, ABE is the blend of 30\% acetone, $60 \%$ butanol and $10 \%$ ethanol by volume) displayed combustion characteristics similar to neat diesel while achieving a shorter combustion duration and lower natural flame luminosity [11]. High volatility difference in butanol-diesel blends could lead to puffing and micro-explosion 
phenomena, which were the strongest around the equi-volumetric composition $[7,12]$. In summary, BUT50 (the blend of 50\% n-butanol and 50\% diesel) potentially increased thermal efficiency and decreased emissions when applied in diesel engines. From Table 1, the physical properties of n-hexadecane are similar with those of diesel. Therefore, n-hexadecane is used as a representative for diesel to eliminate the influence of diesel's multicomponents [13]. In this work, BUT50 (the blend of 50\% n-butanol and $50 \%$ n-hexadecane) is chosen as the test fuel.

It is meaningful to investigate evaporation and puffing characteristics because they are key factors influencing the engine performance. The droplet suspension technology is widely used to investigate the characteristics of single droplet. In this technology, a droplet is suspended on a suspension wire and transported into a hot and stagnant environment. The suspension wire mainly includes silica fiber [14, 15], silicon carbide fiber [16-19] and thermocouple [10, 13]. The main limitation of this technology is that the initial droplet size can only vary from 0.6 to $1.23 \mathrm{~mm}$ when the diameter of suspension wire varies from 0.1 to $0.2 \mathrm{~mm}[13-15,17,19]$. The droplet is likely to fall down from the suspension wire if the droplet size is too big. However, the suspension wire has a significant impact on the droplet if the droplet size is too small. In spite of the limitation, this technology is still applied in many researches of single droplet, including evaporation [14, 20-22], puffing [10, 13, 15], micro-explosion [23-25] and combustion $[16-18,23,24,26,27]$. In the present work, a thermocouple is used as the suspension wire because of its convenient and synchronous measurement of droplet temperature and images.

By the droplet suspension technology, some experiments were carried out to investigate the effect of ambient temperature on evaporation and puffing characteristics. Hashimoto et al. [22] researched the evaporation characteristics of single droplet of palm methyl ester under ambient temperature from 473 to $873 \mathrm{~K}$. The results showed that the initial heating period and droplet lifetime decreased with increasing the ambient temperature. The average evaporation coefficient increased with the increase of ambient temperature because higher ambient temperature led to bigger Spalding transfer number. Similar results were also reported in Refs. [30, 31]. Ma et al. [15] researched evaporation and puffing characteristics of single droplet of acetone-butanol-ethanol (ABE) and diesel blends under ambient temperature from 423 to $823 \mathrm{~K}$. The droplet lifetimes of $\mathrm{ABE}$ and diesel decreased with the increase of ambient temperature. The difference of droplet lifetimes between ABE and diesel became smaller at high temperature. Furthermore, the puffing phenomenon could be observed in the experiments of ABE-diesel blends. The puffing strength increased 
with increasing ambient temperature. Han et al. [13] researched evaporation and puffing characteristics of benzyl azides-hexadecane blends under ambient temperature from 473 to $773 \mathrm{~K}$. The lifetime decrease of benzyl azides-hexadecane blend was more than that of dodecane-hexadecane blend with increasing ambient temperature. This was because the inner reaction of benzyl azides enhanced the puffing phenomenon and improved the evaporation process. Furthermore, the reduction of fluctuation evaporation phase played a significant role in the decrease of droplet lifetime. Han et al. [10] also studied the evaporation and puffing of an ethanol-diesel-biodiesel droplet. The DE10 (the blend of 85\% diesel, 10\% ethanol and 5\% biodiesel) droplet displayed a three-phase evaporation process, including transient heating, fluctuation evaporation and equilibrium evaporation phases. All the three phases decreased with the increase of ambient temperature. However, the percentages for each phase approximately remained identical when the ambient temperature changed from 623 to $723 \mathrm{~K}$.

As review above, the researches of ambient temperature are focused on the effect of ambient temperature on evaporation coefficient, droplet lifetime and durations of the three phases. The novelty of this work is that some new parameters are proposed to quantitatively analyze the puffing process. These parameters include temperature increase rate, similarity degree, deformation degree, the rate of bubble expansion and four characteristic temperatures.

\section{Experimental apparatus and methods}

Fig. 1 shows the schematic diagram and photograph of experimental apparatus in this work. The experimental apparatus includes three main systems, namely a heating system, a droplet generation and transport system and a data acquisition system. The heating system contains a heating chamber, six heating rods and a temperature controller. Fig. 2 shows the detailed schematic diagram of the heating chamber. The inner structure of heating chamber is a cylinder with a diameter of $100 \mathrm{~mm}$ and a height of $100 \mathrm{~mm}$. Six heating rods are evenly installed in a $90 \mathrm{~mm}$ circle on the top of the heating chamber. The power of each heating rod is $600 \mathrm{~W}$. Two optical windows are installed on the front and rear of the heating chamber. The diameter of the optical window is $60 \mathrm{~mm}$ and its thickness is $15 \mathrm{~mm}$. Two $10 \mathrm{~mm}$ passes are on the top and bottom of the heating chamber respectively. The top pass is for droplet transport and the bottom one is for a K-type thermocouple installation. The thermocouple is inserted into the inner of the heating chamber through the bottom pass to monitor the temperature change inside the heating chamber. The thermocouple is connected to a proportional-integral-differential (PID) temperature controller with a control accuracy of $\pm 2 \mathrm{~K}$. 


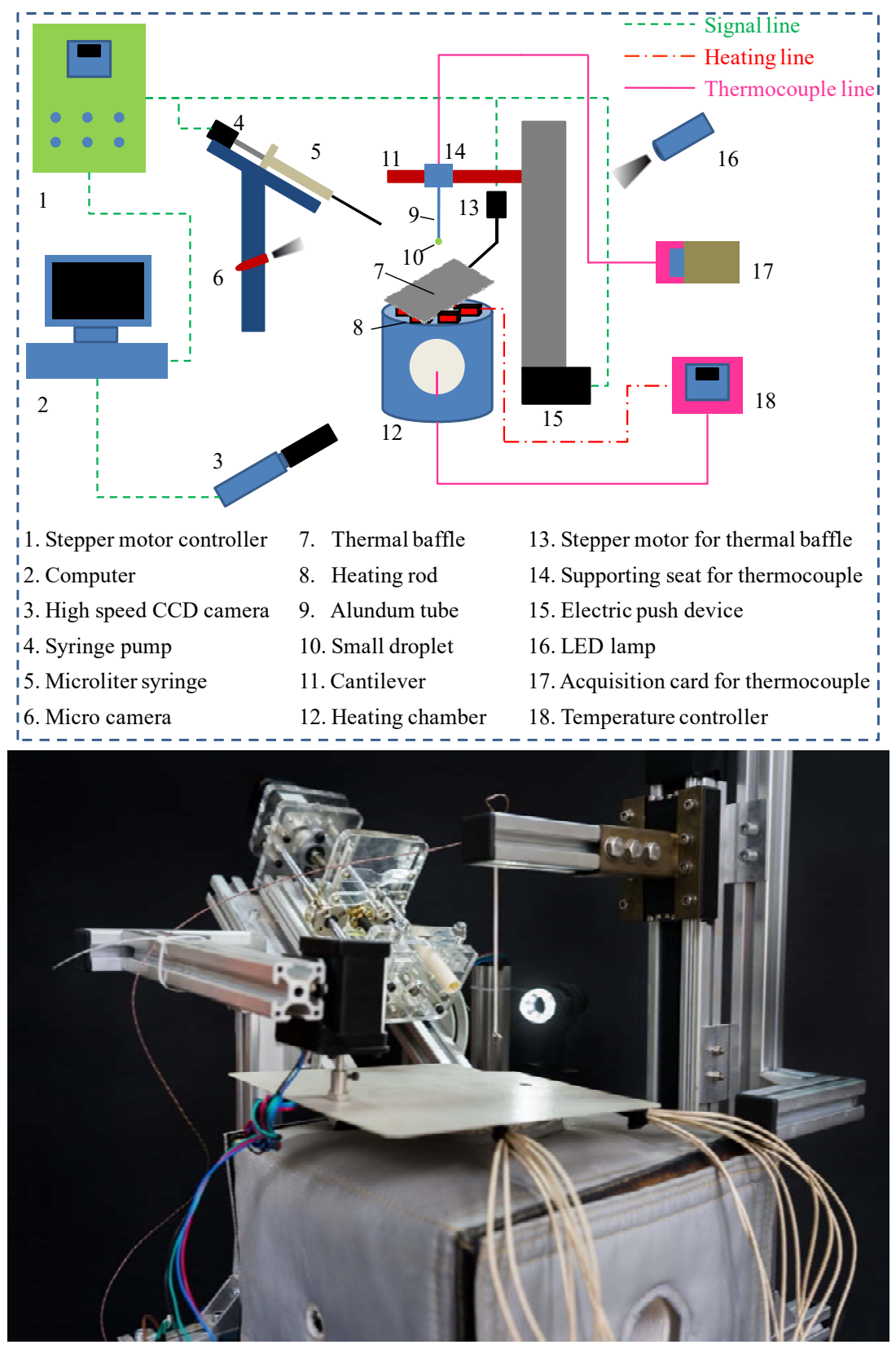

Fig. 1. Schematic diagram and photograph of the experimental apparatus.

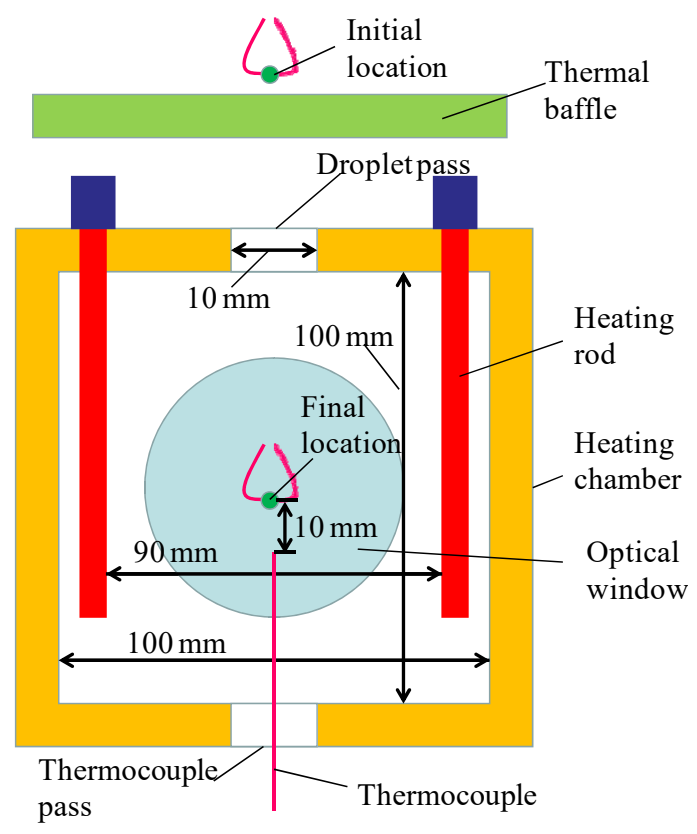

Fig. 2. Schematic diagram of the heating chamber. 
The droplet generation and transport system contains droplet generation, droplet transport and heat insulation parts. All three parts are connected to a stepper motor controller. The droplet generation part includes a syringe pump, a microliter syringe and a thermocouple of bare wire (Fig. 1). The diameter of bare wire is $0.127 \mathrm{~mm}$. Fig. 3 shows the schematic diagram of the droplet generation process. Firstly, a certain amount of test fuel is stored in the microliter syringe. A copper wire is inserted into the syringe needle. The diameters of syringe needle and copper wire are 0.5 and $0.1 \mathrm{~mm}$. Secondly, the microliter syringe moves right and the motion must ensure the contact between the syringe needle and thermocouple wire. A small droplet will adhere to the needle surface when the bulge of syringe tube gets in touch with the baffle. Thirdly, the microliter syringe moves left and the small droplet can adhere to the junction between thermocouple wire and syringe needle. With the left motion of microliter syringe, the droplet is transferred from the syringe needle to the copper wire. The diameter of the needle $(0.5 \mathrm{~mm})$ is significantly thicker than that of copper wire $(0.1 \mathrm{~mm})$ and thermocouple wire $(0.127 \mathrm{~mm})$. It is difficult to directly transfer the droplet from the needle surface to thermocouple wire. The copper wire is a transition between the syringe needle and thermocouple wire. Finally, the microliter syringe moves to the initial location and the small droplet is suspended on the thermocouple junction. The droplet transport part includes an alundum tube, a cantilever, a supporting seat and an electric push device (see Fig. 1). The thermocouple of bare wire is installed inside the alundum tube to prevent from the high temperature environment. The alundum tube is fixed to the cantilever through the supporting seat. The cantilever is connected to the sliding block of the electric push device. The sliding block is driven by a stepper motor through a rubber belt. In the process of droplet transport, the distance is $150 \mathrm{~mm}$ between the initial and final locations. The fastest speed of the sliding block is $400 \mathrm{~mm} / \mathrm{s}$ and the shortest transport time is less than $400 \mathrm{~ms}$. When the droplet is at the initial location, the droplet and heating chamber are separated by a thermal baffle which is also controlled by the stepper motor controller. The purpose of thermal baffle is to decrease the heating effect of high temperature gas because of the buoyancy effect. In this study, it is defined as the initial time when the droplet arrives at the final location [10]. At the final location, the distance is $10 \mathrm{~mm}$ between the small droplet and thermocouple tip (see Fig. 2).

The data acquisition system includes image and temperature acquisition parts. The image acquisition part includes a high speed CCD camera (IDT Motion Pro Y4-S1) and a LED lamp. A tele-macro lens (Nikon Micro-ED 200mm f/4) is installed in the front of the camera. The spatial resolution is 76 pixels $/ \mathrm{mm}$ when the distance is $250 \mathrm{~mm}$ between the tele-macro lens and small 
droplet at the final location of droplet transport. The temperature acquisition part includes a temperature acquisition card and some thermocouples. Table 2 shows the detailed settings for the image and temperature acquisition parts.


Baffle

tube
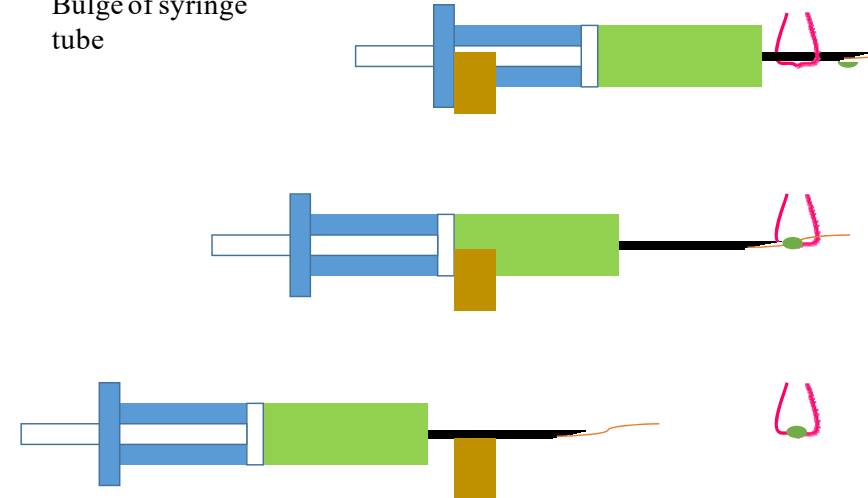

(4)

Fig. 3. Schematic diagram of the droplet generation process.

Table 2 Detailed settings for data acquisition system.

\begin{tabular}{lll}
\hline Device name & Parameter & Value \\
\hline & Resolution & $1024 \times 1024$ pixels \\
High speed CCD camera & Exposure time & $200 \mu \mathrm{s}$ \\
& Shoot frequency & $2000 \mathrm{fps}$ \\
Tele-macro lens & Aperture & $32 \mathrm{~mm}$ \\
LED lamp & Power & $40 \mathrm{~W}$ \\
Temperature acquisition card & Sampling frequency & $100 \mathrm{~Hz}$ \\
\hline
\end{tabular}

Fig. 4 shows the schematic diagram of the image processing program in this work. Firstly, the region of interest (ROI, $300 \times 300$ pixels $)$ is extracted from the original images $(1024 \times 1024$ pixels $)$ to speed up the computation. Secondly, the images of droplet and thermocouple are obtained through the binarization process. The threshold of the binarization process is calculated by $I=\left(2 I_{d r o}+I_{a m b}\right) / 3$, where $I_{\text {dro }}$ and $I_{\text {amb }}$ are the light intensities of the droplet and ambient environment [32]. Thirdly, the image of thermocouple is eliminated and only the image of droplet is preserved. Fourthly, the droplet boundary can be extracted from the droplet image. Finally, the similarity and deformation degrees can be calculated by Eqs. (1) and (2),

$$
\begin{gathered}
\text { Similarity }=100 \%-\sqrt{\frac{\sum_{i, j}^{300 \times 300}\left(P_{1}(i, j)-P_{2}(i, j)\right)^{2}}{300 \times 300}} \\
\text { Deformation }=\frac{S_{c}}{S}=\frac{C^{2}}{4 \pi S}
\end{gathered}
$$

where $\mathrm{P}$ represents the images of ROI, the subscripts 1 and 2 are the first and second images of two adjacent images, $\mathrm{S}_{\mathrm{c}}$ is the 
circumference equivalent projected area, $\mathrm{C}$ and $\mathrm{S}$ are the actual circumference and projected area of the small droplet. The similarity degree reflects the transient variation of droplet image and the deformation degree reflects the deviation of droplet image from a standard circle. More details on the image processing program can be found in Ref. [33, 34]. In the present experiments, analytical grade n-butanol $(\geq 99.7 \%)$ and $n$-hexadecane $(\geq 99.5 \%)$ are supplied by the Aladdin Corporation. The ambient temperatures of 638,688 and $738 \mathrm{~K}$ are chosen because the puffing characteristics are obviously different under these three temperatures. The purpose of this work is to analyze the effect of ambient temperature on puffing characteristics.

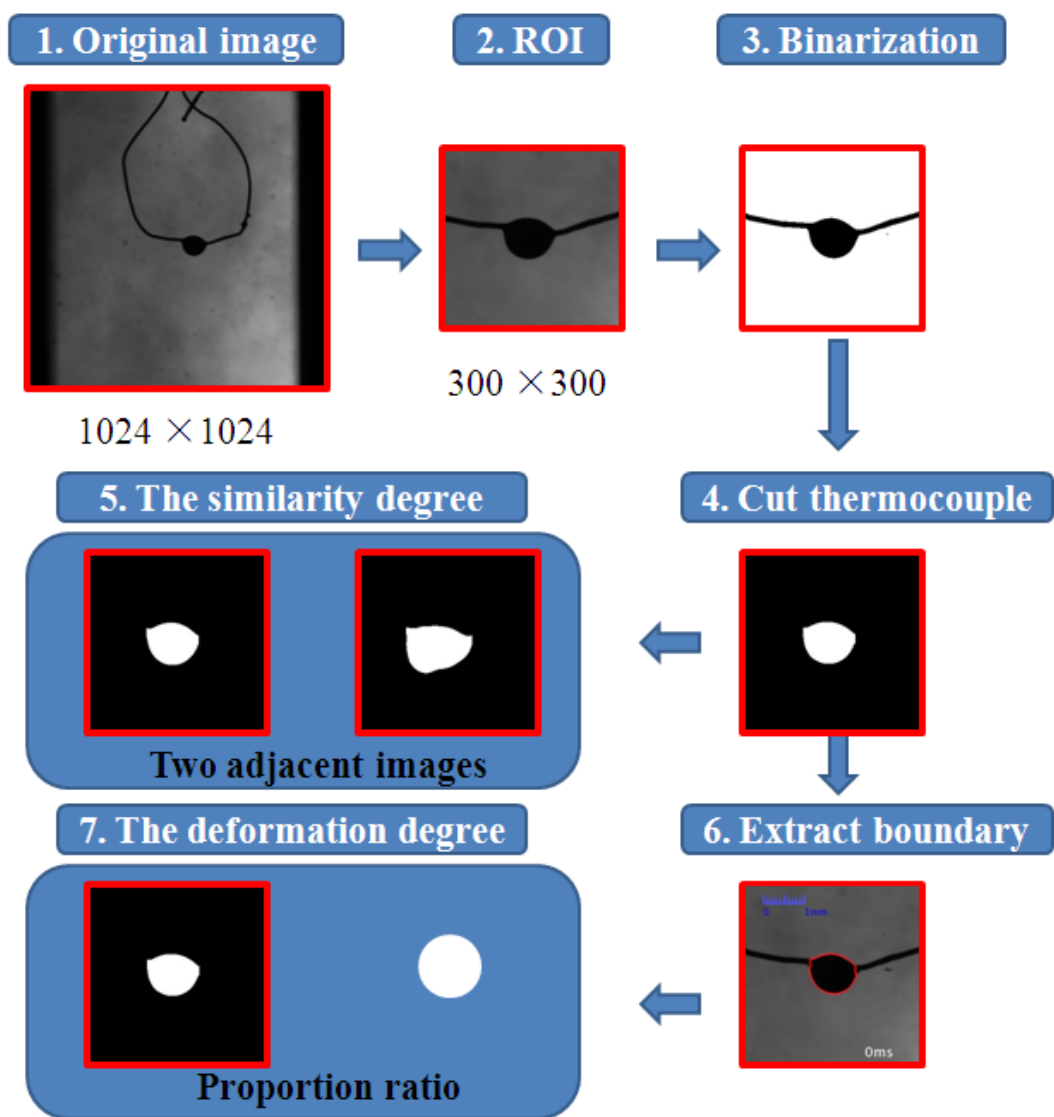

Fig. 4. Schematic diagram of the image processing program.

\section{Results and discussions}

Fig. 5 shows the puffing process of BUT50 (the blend of 50\% n-butanol and 50\% n-hexadecane) at $638 \mathrm{~K}$. The droplet size and shape do not change from 0.000 to $0.370 \mathrm{~s} / \mathrm{mm}^{2}$. Although no obvious bubble can be observed from 0.370 to $0.428 \mathrm{~s} / \mathrm{mm}^{2}$, the droplet size at $0.428 \mathrm{~s} / \mathrm{mm}^{2}$ is slightly larger than that at $0.370 \mathrm{~s} / \mathrm{mm}^{2}$. The puffing phenomenon can be observed at $0.430 \mathrm{~s} / \mathrm{mm}^{2}$, indicating that a small bubble is formed inside the droplet. From 0.506 to $0.582 \mathrm{~s} / \mathrm{mm}^{2}$, a bubble quickly expands and reaches the maximum size at $0.582 \mathrm{~s} / \mathrm{mm}^{2}$. Soon later, the bubble rupture occurs and violent droplet deformation can be observed at 0.584 $\mathrm{s} / \mathrm{mm}^{2}$. Violent droplet deformation leads to a child droplet departure from the mother droplet at $0.586 \mathrm{~s} / \mathrm{mm}^{2}$. The droplet spends 
a long time on the recovery of droplet shape and reaches a stable state at $0.705 \mathrm{~s} / \mathrm{mm}^{2}$. The slight droplet deformation caused by the ejection of n-butanol vapor can be observed in a long period (such as 0.950 and $0.952 \mathrm{~s} / \mathrm{mm}^{2}$ ). A spike-like uplift is also caused by the ejection of n-butanol vapor and occasionally found on the droplet surface at $1.035 \mathrm{~s} / \mathrm{mm}^{2}$. After $1.667 \mathrm{~s} / \mathrm{mm}^{2}$, the droplet enters a stable state again until the droplet evaporation is finished at $2.499 \mathrm{~s} / \mathrm{mm}^{2}$. The images of BUT50 at $688 \mathrm{~K}$ are similar with those at $638 \mathrm{~K}$. Therefore, the images at $688 \mathrm{~K}$ are not listed because of limited space.
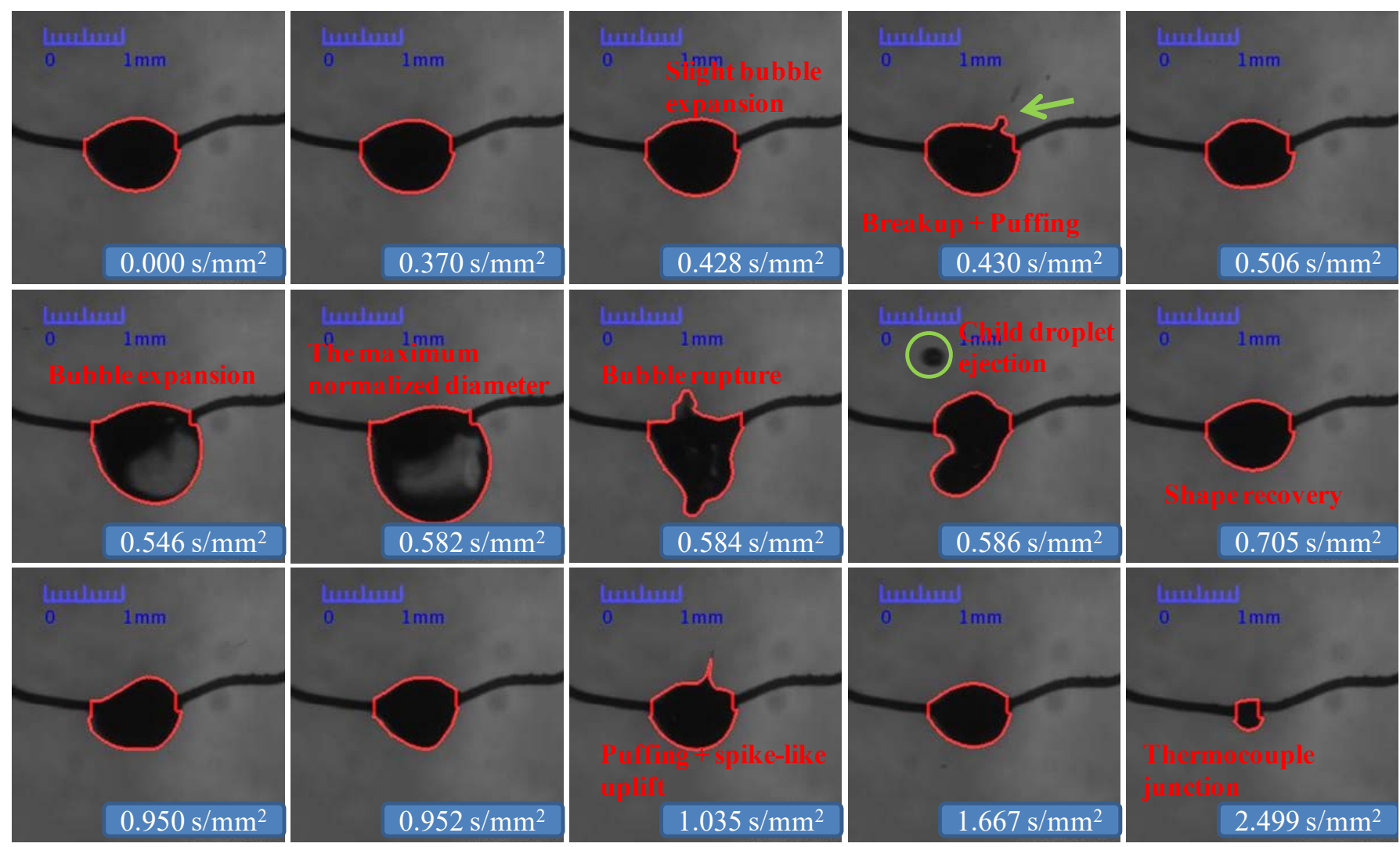

Fig. 5. Puffing process of BUT50 at $638 \mathrm{~K}$.

Fig. 6 shows the puffing process of BUT50 at $738 \mathrm{~K}$. Before $0.179 \mathrm{~s} / \mathrm{mm}^{2}$, no bubble can be found and the droplet goes through the stable evaporation. Many periodic processes can be observed after $0.179 \mathrm{~s} / \mathrm{mm}^{2}$. Every periodic process contains bubble formation, bubble expansion, bubble rupture and droplet recovery. Only two typical periodic processes are shown in Fig. 6 . For the first periodic process, a bubble gradually expands from 0.269 to $0.291 \mathrm{~s} / \mathrm{mm}^{2}$ and finally breaks up at $0.292 \mathrm{~s} / \mathrm{mm}^{2}$. In the period from 0.292 to $0.295 \mathrm{~s} / \mathrm{mm}^{2}$, the droplet size sharply decreases along with violent deformation because of the departure of n-butanol vapor. Before the droplet recovers to the stable state, another obvious bubble observed at $0.328 \mathrm{~s} / \mathrm{mm}^{2}$ leads to the droplet deformation again. For the second periodic process, the bubble expansion is from 0.416 to $0.435 \mathrm{~s} / \mathrm{mm}^{2}$. The bubble rupture occurs and two child droplets are ejected from the mother droplet at $0.436 \mathrm{~s} / \mathrm{mm}^{2}$. After $1.007 \mathrm{~s} / \mathrm{mm}^{2}$, no obvious 
deformation can be observed apart from the period from 1.483 to $1.485 \mathrm{~s} / \mathrm{mm}^{2}$. The droplet size abruptly decreases at $1.485 \mathrm{~s} / \mathrm{mm}^{2}$.

The phenomenon indicates that a small bubble does not continue to expand and is stably contained inside the droplet from 1.007

to $1.483 \mathrm{~s} / \mathrm{mm}^{2}$. Finally, the thermocouple junction is exposed at $1.598 \mathrm{~s} / \mathrm{mm}^{2}$, indicating that the droplet is completely evaporated.
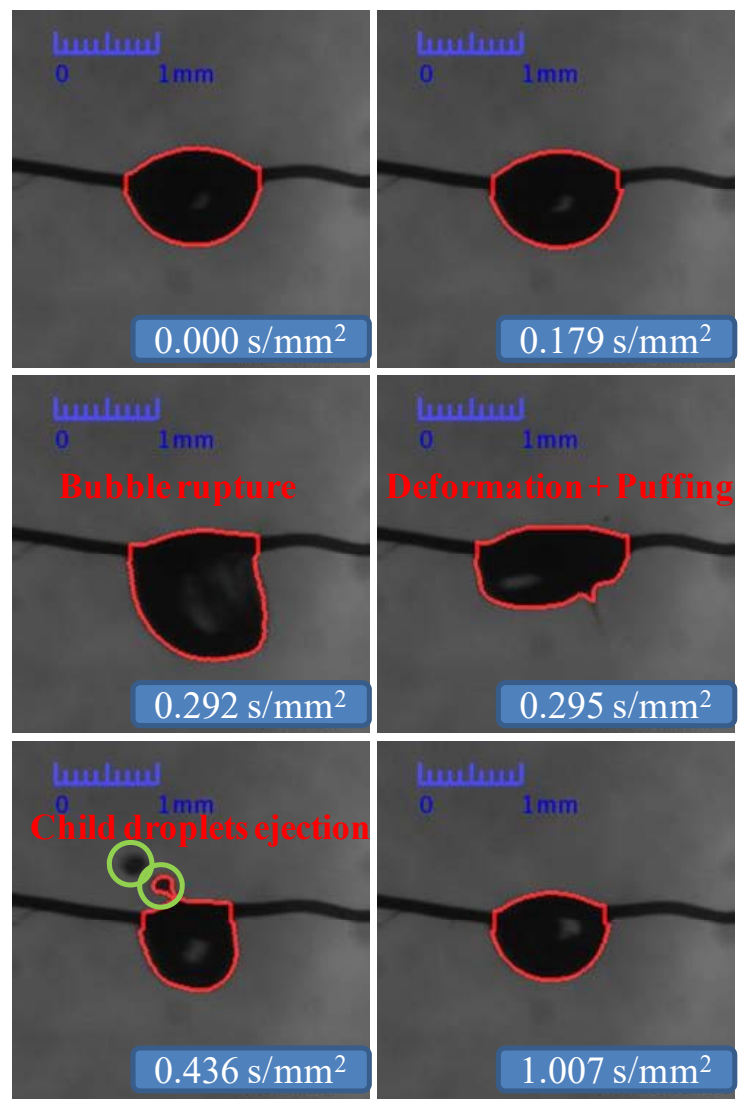
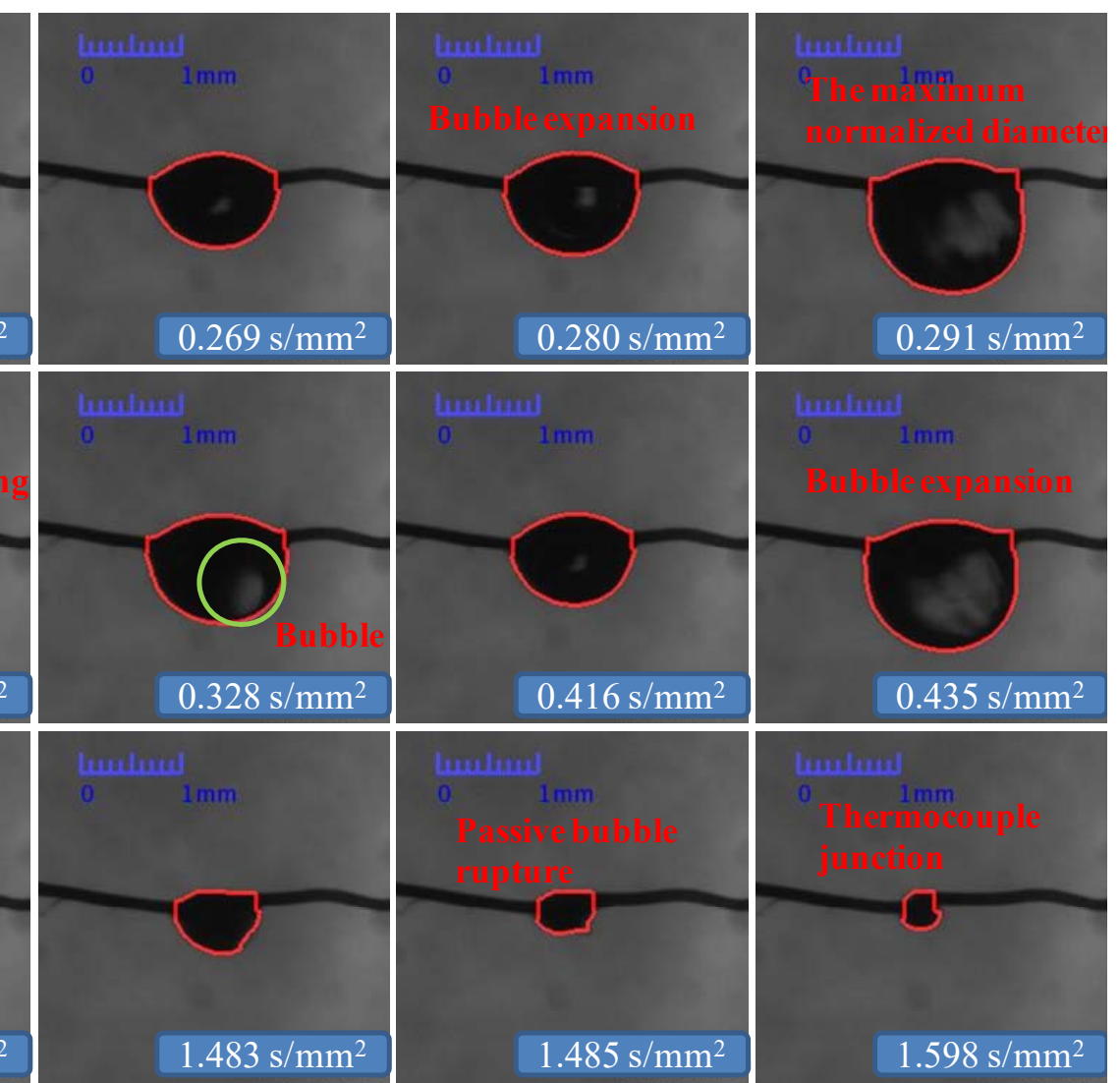

Fig. 6. Puffing process of BUT50 at $738 \mathrm{~K}$.

Fig. 7 shows the normalized squared diameter, droplet temperature, similarity degree and deformation degree at 638 and 738 K. For each ambient temperature, only a set of experimental data is listed to ensure figure conciseness. As shown in Fig. 7, BUT50 droplet displays the three-phase puffing process under the two ambient temperatures, including the transient heating, fluctuation evaporation and equilibrium evaporation phases. The three phases of the puffing process can be distinguished by the similarity degree [33]. The evaporation process is stable in the transient heating and equilibrium evaporation phases. Most of the similarity degrees are more than $97 \%$ in the two phases. Therefore, the similarity degree of $97 \%$ is regarded as the dividing point between normal evaporation and fluctuation evaporation in this work. The relevant images of the experimental data of 638 and $738 \mathrm{~K}$ have been shown in Fig. 5 and Fig. 6. 

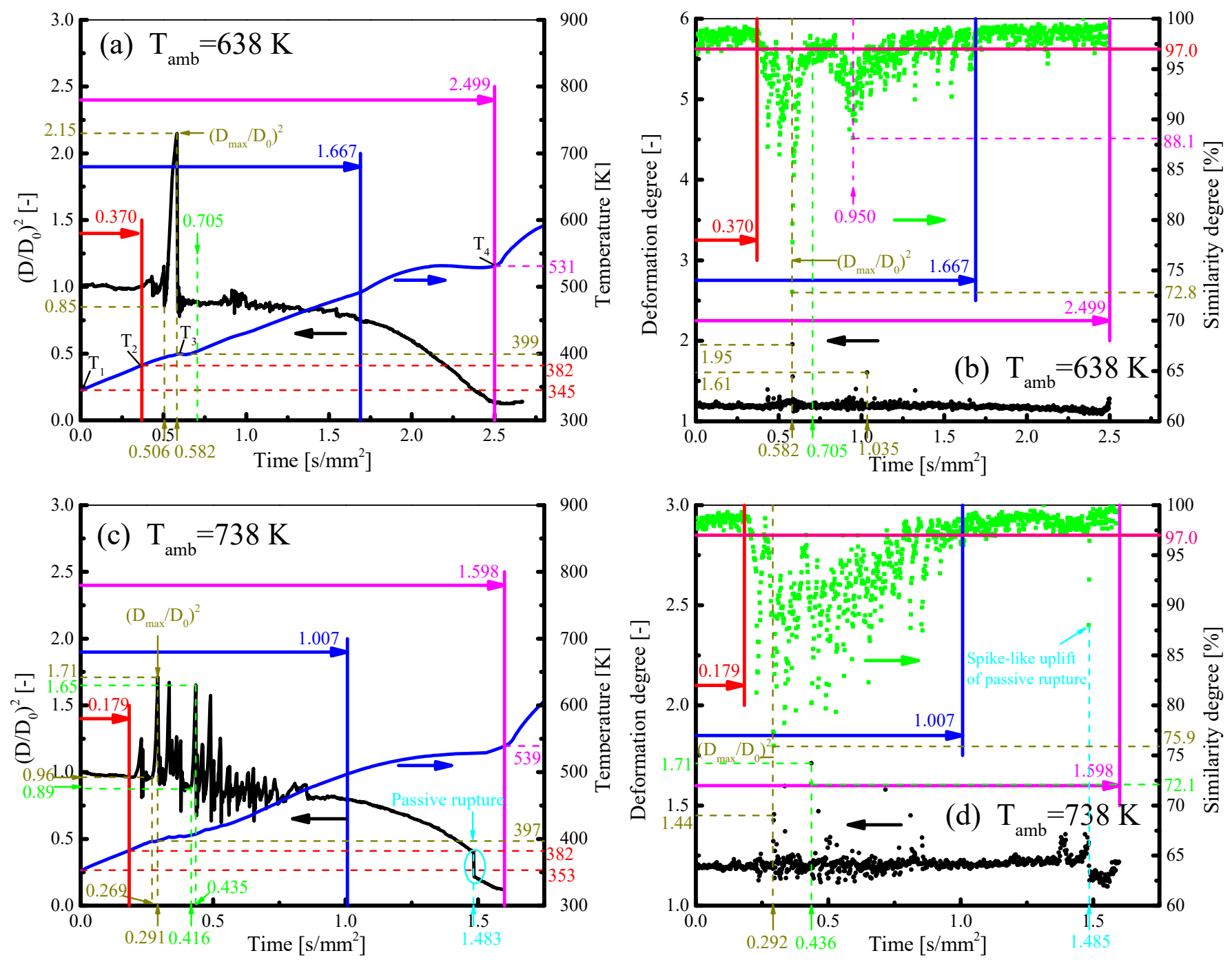

Fig. 7. Normalized squared diameter, droplet temperature, similarity degree and deformation degree at 638 and $738 \mathrm{~K}$.

Fig. 7 (a) and (b) shows that no obvious fluctuation can be observed in the curves of normalized squared diameter and similarity degree before $0.370 \mathrm{~s} / \mathrm{mm}^{2}$. Soon later, the similarity degree sharply decreases due to bubble expansion. The turning point of $0.370 \mathrm{~s} / \mathrm{mm}^{2}$ is regarded as the dividing point between the transient heating and fluctuation evaporation phases. The normalized squared diameter sharply increases from 0.85 to 2.15 in the period from 0.506 to $0.582 \mathrm{~s} / \mathrm{mm}^{2}$. Eq. (3) is used to describe the rate of bubble expansion,

$$
k=\frac{\left(D / D_{0}\right)_{t o p}^{2}-\left(D / D_{0}\right)_{b o t}^{2}}{\tau_{\text {top }}-\tau_{b o t}}
$$

where $\left(\mathrm{D} / \mathrm{D}_{0}\right)_{\text {top }}^{2}=2.15,\left(\mathrm{D} / \mathrm{D}_{0}\right)^{2}$ bot $=0.85, \tau_{\text {top }}=0.582 \mathrm{~s} / \mathrm{mm}^{2}$ and $\tau_{\text {bot }}=0.506 \mathrm{~s} / \mathrm{mm}^{2}$. Therefore, the expansion rate of $638 \mathrm{~K}$ is 17.1 $\mathrm{mm}^{2} / \mathrm{s}$. $\left(\mathrm{D}_{\max } / \mathrm{D}_{0}\right)^{2}$ is the maximum value of normalized squared diameter. The similarity degree of $638 \mathrm{~K}$ firstly decreases and then increases around the time of $\left(\mathrm{D}_{\max } / \mathrm{D}_{0}\right)^{2}$. The decrease of similarity degree is caused by the fast bubble expansion (from 0.506 
to $0.582 \mathrm{~s} / \mathrm{mm}^{2}$ in Fig. 5). The increase of similarity degree is caused by the recovery of droplet deformation because surface tension tries to change the droplet into a sphere (from 0.584 to $0.705 \mathrm{~s} / \mathrm{mm}^{2}$ in Fig. 5). Because of violent droplet deformation after bubble rupture, the minimum similarity degree is $72.8 \%$ and the maximum deformation degree is 1.95 at $0.582 \mathrm{~s} / \mathrm{mm}^{2}$. From 0.705 to $1.667 \mathrm{~s} / \mathrm{mm}^{2}$, high-frequency and weak fluctuations can be observed in the curve of normalized squared diameter. The phenomenon indicates that no sufficient bubble can be formed inside the droplet. During the same period, obvious fluctuations can be observed in the curve of similarity degree. For example, the similarity degree is $88.1 \%$ at $0.950 \mathrm{~s} / \mathrm{mm}^{2}$. This is because the ejection of n-butanol vapor leads to continuous droplet deformation (such as 0.950 and $0.952 \mathrm{~s} / \mathrm{mm}^{2}$ in Fig. 5). Another high deformation degree is 1.61 at $1.035 \mathrm{~s} / \mathrm{mm}^{2}$. A spike-like uplift caused by n-butanol vapor ejection leads to the high deformation degree. After $1.667 \mathrm{~s} / \mathrm{mm}^{2}$, most of the similarity degrees are in the range between $97 \%$ and $100 \%$ again. The normalized squared diameter gradually decreases and no fluctuation can be found in the period from 1.667 to $2.499 \mathrm{~s} / \mathrm{mm}^{2}$. This phenomenon indicates the small droplet undergoes stable evaporation after $1.667 \mathrm{~s} / \mathrm{mm}^{2}$. Therefore, the time of $1.667 \mathrm{~s} / \mathrm{mm}^{2}$ is the dividing point between the fluctuation evaporation and equilibrium evaporation phases.

Fig. 7 (c) and (d) show the puffing characteristics of $738 \mathrm{~K}$. Only an obvious fluctuation can be observed in the curve of normalized squared diameter at $638 \mathrm{~K}$. However, the frequency of violent oscillations at $738 \mathrm{~K}$ is significantly higher than that at $638 \mathrm{~K}$ in the curve of normalized squared diameter. The rates of bubble expansion for the two periodic processes in Fig. 6 are 34.1 and $40.0 \mathrm{~mm}^{2} / \mathrm{s}$, which are significantly more than that $\left(17.1 \mathrm{~mm}^{2} / \mathrm{s}\right)$ at $638 \mathrm{~K}$. The average values of $\left(\mathrm{D}_{\max } / \mathrm{D}_{0}\right)^{2}$ are $1.99,1.77$ and 1.65 at 638,688 and $738 \mathrm{~K}$ respectively, as shown in Fig. 8. The average $\left(\mathrm{D}_{\max } / \mathrm{D}_{0}\right)^{2}$ decreases gradually with the increase of ambient temperature. The uncertainty of $\left(D_{\max } / D_{0}\right)^{2}$ is calculated by Eq. (4) according to the A-type standard uncertainty.

$$
u_{A}=\sqrt{\frac{\left(x_{1}-\bar{x}\right)^{2}+\left(x_{2}-\bar{x}\right)^{2}+\cdots+\left(x_{n}-\bar{x}\right)^{2}}{n-1}}
$$

where $\mathrm{u}_{\mathrm{A}}$ is the A-type standard uncertainty, $\mathrm{x}_{1}, \mathrm{x}_{2}, \ldots, \mathrm{x}_{\mathrm{n}}$ are experimental values, $\overline{\mathrm{x}}$ is the average value of experimental values, $\mathrm{n}$ is the number of experimental samples. Higher ambient temperature leads to the generation of more n-butanol vapor inside the droplet when more heat is transferred to the droplet inner. The higher rate of bubble expansion, caused by more n-butanol vapor, makes the droplet breakup more easily $[35,36]$. Easy bubble rupture leads to high frequency of fluctuation and low $\left(\mathrm{D}_{\text {max }} / \mathrm{D}_{0}\right)^{2}$ at 738 K. Similar with the normalized squared diameter, violent fluctuations of similarity degree can be observed in the entire 
fluctuation evaporation phase of $738 \mathrm{~K}$ (Fig. 7 (d)). The interval time between two obvious fluctuations is very short because there are many obvious fluctuations in the fluctuation evaporation phase. Therefore, the droplet is difficult to recover to the stable state within the short recovery time (at $0.328 \mathrm{~s} / \mathrm{mm}^{2}$ in Fig. 6). Furthermore, a bluff-like shrinkage can be found at $1.483 \mathrm{~s} / \mathrm{mm}^{2}$ in Fig. 7 (c). At the same time, a spike-like uplift can be observed in the curve of similarity degree (Fig. 7 (d)). The lowest value of the spike-like uplift is much lower than $97 \%$ because passive rupture leads to the sharp decrease of droplet size (from 1.483 to 1.485 $\mathrm{s} / \mathrm{mm}^{2}$ in Fig. 6).



Fig. 8. Effect of ambient temperature on average $\left(D_{\max } / D_{0}\right)^{2}$.

Fig. 9 shows the correlation between droplet temperature and transient temperature growth rate at 638 and $738 \mathrm{~K}$. The transient temperature growth rate is defined by Eq. (5),

$$
\lambda_{\text {tran }}=\frac{T_{b a c}-T_{\text {fro }}}{\Delta t}
$$

where $\mathrm{T}_{\text {fro }}$ and $\mathrm{T}_{\text {bac }}$ are the front and back temperatures of two adjacent droplet temperatures. $\Delta \mathrm{t}$ is the normalized interval time of temperature data and equals to $8.64 \times 10^{-3} \mathrm{~s} / \mathrm{mm}^{2}$. Three turning points can be found in Fig. 9 (a). The first turning point is around $0.582 \mathrm{~s} / \mathrm{mm}^{2}$ and corresponds to the time of $\left(\mathrm{D}_{\max } / \mathrm{D}_{0}\right)^{2}$. The transient temperature growth rate decreases before $0.582 \mathrm{~s} / \mathrm{mm}^{2}$ because fast bubble expansion absorbs much heat from the droplet. The transient temperature growth rate increases after 0.582 $\mathrm{s} / \mathrm{mm}^{2}$ because the inner evaporation of n-butanol gradually weakens inside the droplet. The second turning point is around 1.667 $\mathrm{s} / \mathrm{mm}^{2}$, which is the dividing point of fluctuation evaporation and equilibrium evaporation phases. The transient temperature growth rate increases because most of n-butanol has left the small droplet as n-butanol vapor after $1.667 \mathrm{~s} / \mathrm{mm}^{2}$. The cooling effect 
of n-butanol is stronger than that of n-hexadecane because the latent heat of n-butanol $\left(5.85 \times 10^{5} \mathrm{~J} / \mathrm{kg}\right)$ is much larger than that of n-hexadecane $\left(2.74 \times 10^{5} \mathrm{~J} / \mathrm{kg}\right)$. Soon later, the transient temperature growth rate gradually decreases because the droplet temperature is approaching the wet temperature. When the droplet temperature equals to the wet temperature, the heat transferred to the droplet surface equals to the latent heat of evaporation. The third turning point is around $2.499 \mathrm{~s} / \mathrm{mm}^{2}$, which is the total lifetime of the droplet. The transient temperature growth rate increases because the thermocouple junction is directly heated by the high temperature gas. Similar with $638 \mathrm{~K}$, three turning points are also found in Fig. 9 (b). The turning points of $1 \#$ are obviously different between 638 and $738 \mathrm{~K}$. The heat absorption of bubble expansion leads to the turning of temperature curve. For the turning point $1 \#$ in Fig. 9, only a fluctuation is found at $638 \mathrm{~K}$ and many fluctuations are detected at $738 \mathrm{~K}$. This is because a bubble expansion is found in Fig. 7 (a) and many bubble expansions are contained in Fig. 7 (c). For the turning point $1 \#$ at $738 \mathrm{~K}$, the tendency of temperature increase rate gradually increases because butanol content gradually decreases in the droplet.
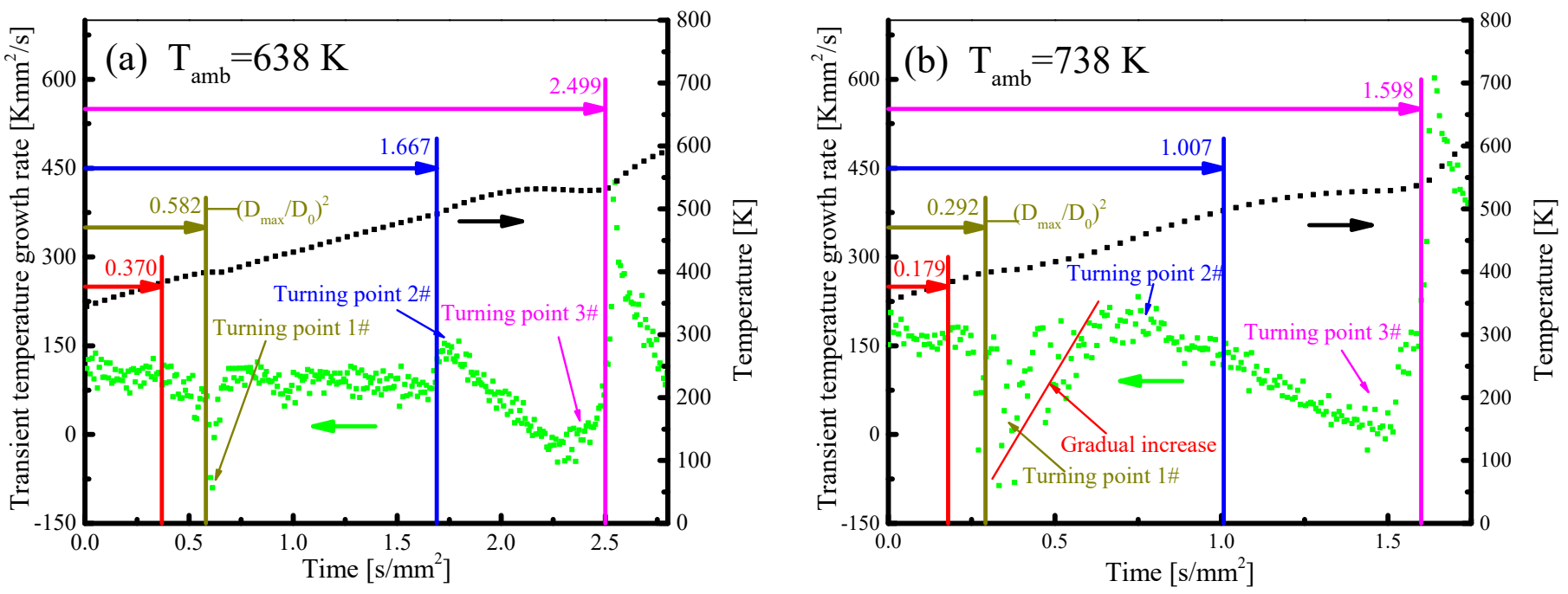

Fig. 9. Relationship between droplet temperature and temperature increase rate at 638 and $738 \mathrm{~K}$.

Fig. 10 shows the effect of ambient temperature on characteristic droplet temperatures. Four characteristic temperatures are defined in this work, including the droplet temperatures at the start $\left(\mathrm{T}_{1}\right)$ and end $\left(\mathrm{T}_{2}\right)$ of the transient heating phase, at the time of $\left(D_{\max } / D_{0}\right)^{2}\left(T_{3}\right)$ and at the end of total lifetime $\left(T_{4}\right)$. The four characteristic temperatures are also listed in Fig. 7 (a) to better describe them. The uncertainty of characteristic droplet temperature is calculated by Eq. (6) according to the combined standard uncertainty.

$$
u_{C}=\sqrt{\left(u_{A}\right)^{2}+\left(u_{B}\right)^{2}}
$$

where $\mathrm{u}_{\mathrm{A}}, \mathrm{u}_{\mathrm{B}}$ and $\mathrm{u}_{\mathrm{C}}$ are A-type, B-type and combined standard uncertainties. $\mathrm{u}_{\mathrm{A}}$ can be calculated by Eq. (4). $\mathrm{u}_{\mathrm{B}}$ equals to $\pm 2.5 \mathrm{~K}$ 
in the specification of thermocouple. All $\mathrm{T}_{1}$ values are approximately unchanged and around $354 \mathrm{~K}$. This indicates that different ambient temperatures have insignificant effect on the initial droplet temperature. $\mathrm{All}_{2}$ values are around $386 \mathrm{~K}$, which is slightly lower than the boiling point of n-butanol $(390 \mathrm{~K})$. With the heating process of the thermocouple, the partial temperature near the thermocouple surface is likely to be higher than the boiling point of n-butanol (390 K). Therefore, a small bubble can be generated on the thermocouple surface. After the end of transient heating phase, obvious fluctuations can be found in the curves of the normalized squared diameter and similarity degree. All $\mathrm{T}_{3}$ values are around $403 \mathrm{~K}$, which is slightly higher than the boiling point of n-butanol $(390 \mathrm{~K})$. A certain degree of superheat can be formed inside the droplet. At the same time, a large proportion of n-butanol still exists inside the droplet. Therefore, a lot of n-butanol vapor is generated and an obvious fluctuation can be found in the normalized squared diameter. All $\mathrm{T}_{4}$ values are around $540 \mathrm{~K}$, which is slightly less than the boiling point of $\mathrm{n}$-hexadecane $(560 \mathrm{~K})$. At the end of droplet lifetime, the wet temperature is slightly lower than the boiling point of n-hexadecane because only n-hexadecane is contained in the droplet [37].

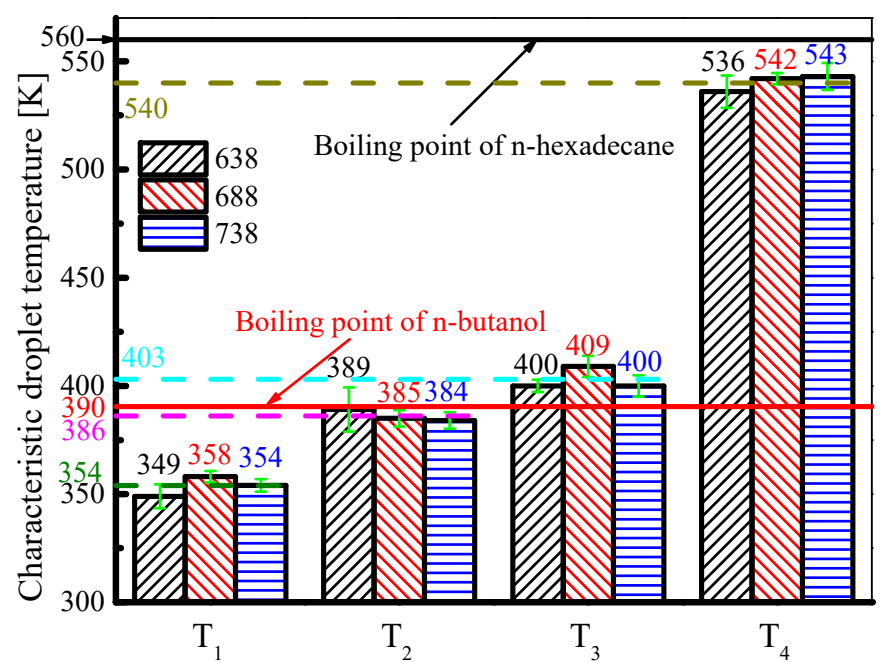

Fig. 10. Effect of ambient temperature on characteristic droplet temperatures.

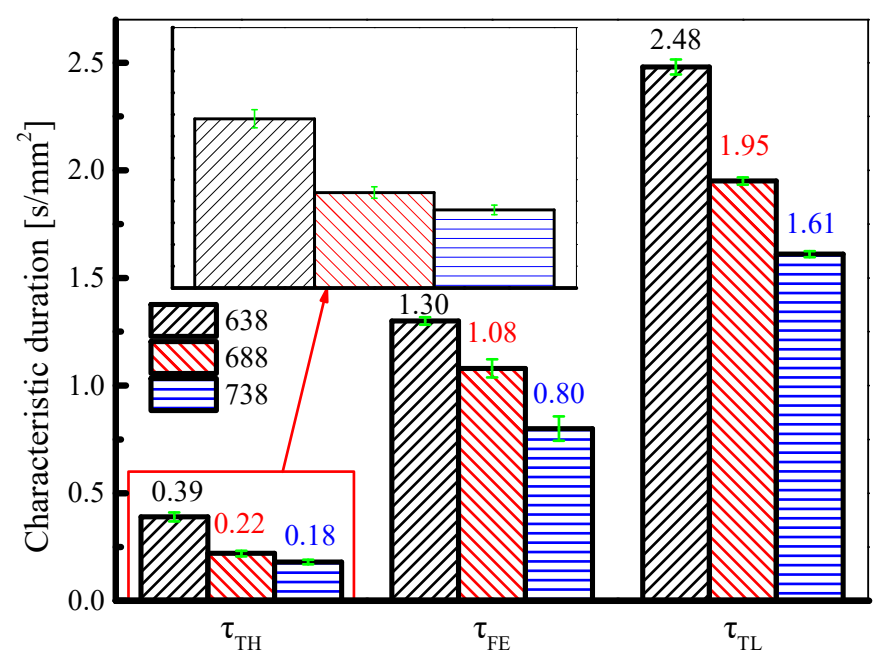

Fig. 11. Effect of ambient temperature on characteristic durations.

Fig. 11 shows the effect of ambient temperature on characteristic durations. Three characteristic durations are defined, including the durations of the transient heating phase $\left(\mathrm{t}_{\mathrm{TH}}\right)$, fluctuation evaporation phase $\left(\mathrm{t}_{\mathrm{FE}}\right)$ and the total life of the droplet evaporation $\left(\mathrm{t}_{\mathrm{TL}}\right)$. The uncertainty of characteristic duration is also calculated by Eq. (4). The average $\mathrm{t}_{\mathrm{TH}}$ values are $0.39,0.22$ and $0.18 \mathrm{~s} / \mathrm{mm}^{2}$ at 638,688 and $738 \mathrm{~K}$, respectively. $\mathrm{t}_{\mathrm{TH}}$ decreases with the increase of ambient temperature. $\mathrm{t}_{\mathrm{TH}}$ reflects the time of puffing occurrence and shorter $\mathrm{t}_{\mathrm{TH}}$ can enhance the combustion efficiency because the puffing process can improve the air-fuel 
mixing process. The droplet reaches the state of bubble formation earlier because higher ambient temperature enhances the heating process. The heating process is described by the temperature growth rate in the transient heating phase $\left(\lambda_{\mathrm{TH}}\right) . \lambda_{\mathrm{TH}}$ can be calculated by Eq. (7) and its uncertainty is defined by Eq. (8) [38].

$$
\begin{gathered}
\lambda_{T H}=\left(T_{2}-T_{1}\right) / t_{T H} \\
\frac{\Delta \lambda_{T H}}{\lambda_{T H}}=\sqrt{\left(\frac{\Delta\left(T_{2}-T_{1}\right)}{T_{2}-T_{1}}\right)^{2}+\left(\frac{\Delta t_{T H}}{t_{T H}}\right)^{2}}
\end{gathered}
$$

where $\Delta \lambda_{\mathrm{TH}}$ is the uncertainty of $\lambda_{\mathrm{TH}}, \Delta \mathrm{t}_{\mathrm{TH}}$ is the uncertainty of $\mathrm{t}_{\mathrm{TH}}$ and calculated by Eq. (4). $\Delta\left(\mathrm{T}_{2}-\mathrm{T}_{1}\right)$ is the uncertainty of $\mathrm{T}_{2}-\mathrm{T}_{1}$ and calculated by Eq. (9),

$$
\Delta\left(\mathrm{T}_{2}-\mathrm{T}_{1}\right)=\sqrt{\left(\Delta T_{2}\right)^{2}+\left(\Delta T_{1}\right)^{2}}
$$

where $\Delta \mathrm{T}_{1}$ and $\Delta \mathrm{T}_{2}$ are the combined uncertainties of $\mathrm{T}_{1}$ and $\mathrm{T}_{2}$ and calculated by Eq. (6). Fig. 12 shows the effect of ambient temperature on $\lambda_{\mathrm{TH}}$. The average $\lambda_{\mathrm{TH}}$ values are $102.56,122.73$ and $166.67 \mathrm{~K} \cdot \mathrm{mm}^{2} / \mathrm{s}$ at 638,688 and $738 \mathrm{~K}$, respectively. $\lambda_{\mathrm{TH}}$ increases with the increase of ambient temperature. The average $t_{\mathrm{FE}}$ values are $1.30,1.08$ and $0.80 \mathrm{~s} / \mathrm{mm}^{2}$ at 638,688 and $738 \mathrm{~K}$. Similarly, $t_{\mathrm{FE}}$ decreases with the increase of the ambient temperature. The higher ambient temperature leads to faster heat transfer, which is needed for the $\mathrm{n}$-butanol evaporation inside the droplet. Furthermore, the total lifetimes $\mathrm{t}_{\mathrm{TL}}$ are $2.48,1.95$ and $1.61 \mathrm{~s} / \mathrm{mm}^{2}$ at 638,688 and $738 \mathrm{~K}$. On one hand, higher ambient temperature leads to higher surface temperature, which can quicken the droplet surface evaporation. On the other hand, higher ambient temperature results in more intensive inner evaporation. More n-butanol in the droplet can leave the droplet as vapor. Strong inner evaporation can lead to violent droplet deformation, which can enhance the surface evaporation by increasing the droplet surface area. Eqs (10) and (11) are introduced to research the contribution of $\mathrm{t}_{\mathrm{TH}}$ and $\mathrm{t}_{\mathrm{FE}}$ to the reduction of $\mathrm{t}_{\mathrm{TL}}$ from low to high ambient temperature [13],

$$
\begin{gathered}
X_{T H}=\frac{t_{T H, L T}-t_{T H, H T}}{t_{T L, L T}-t_{T L, H T}} \\
X_{F E}=\frac{t_{\mathrm{FE}, L T}-t_{\mathrm{FE}, H T}}{t_{T L, L T}-t_{T L, H T}}
\end{gathered}
$$

where subscripts $\mathrm{LT}$ and $\mathrm{HT}$ denote the low and high temperatures. From 638 to $688 \mathrm{~K}, \mathrm{X}_{\mathrm{TH}}=32.69 \%$ and $\mathrm{X}_{\mathrm{FE}}=44.23 \%$. From 688 to $738 \mathrm{~K}, \mathrm{X}_{\mathrm{TH}}=11.43 \%$ and $\mathrm{X}_{\mathrm{FE}}=82.86 \%$. This indicates that the reduction of $\mathrm{t}_{\mathrm{FE}}$ plays a very significant role in the reduction of $\mathrm{t}_{\mathrm{TL}}$. 
Eqs. (12) and (13) calculate the percentages of $\mathrm{t}_{\mathrm{TH}}$ and $\mathrm{t}_{\mathrm{FE}}$ in the total lifetime,

$$
\begin{aligned}
& Y_{T H}=t_{T H} / t_{T L} \\
& Y_{F E}=t_{F E} / t_{T L}
\end{aligned}
$$

where $\mathrm{Y}_{\mathrm{TH}}$ and $\mathrm{Y}_{\mathrm{FE}}$ are the normalized $\mathrm{t}_{\mathrm{TH}}$ and $\mathrm{t}_{\mathrm{FE}}$. The results of $\mathrm{Y}_{\mathrm{TH}}$ and $\mathrm{Y}_{\mathrm{FE}}$ are shown in Fig. 13. With the increase of ambient temperature, $\mathrm{Y}_{\mathrm{TH}}$ and $\mathrm{Y}_{\mathrm{FE}}$ are relatively stable and around $12.71 \%$ and $52.23 \%$ respectively. This indicates that the distribution of the three phases is not changed with the increase of ambient temperature.



Fig. 12. Effect of ambient temperature on $\lambda_{\mathrm{TH}}$.

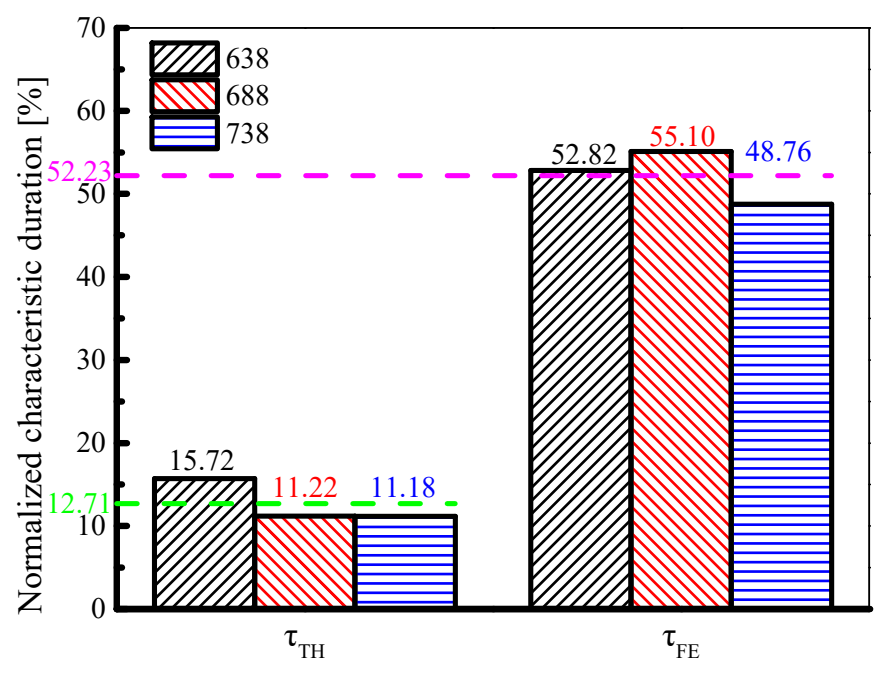

Fig. 13. Effect of ambient temperature on the normalized characteristic durations.

\section{Conclusions}

Droplet suspension technology was used to investigate the puffing characteristics of a butanol-hexadecane (BUT50) droplet under ambient temperature of 638,688 and $738 \mathrm{~K}$. The effect of ambient temperature on the puffing characteristics was analyzed from multiple perspectives, including the droplet image, normalized squared diameter, droplet temperature, temperature growth rate, similarity degree and deformation degree. The main conclusions of the present study can be drawn as follows.

(1). In the fluctuation evaporation phase, the fluctuation frequency of $738 \mathrm{~K}$ is significantly higher than that of $638 \mathrm{~K}$. The average $\left(D_{\max } / D_{0}\right)^{2}$ of $738 \mathrm{~K}$ is lower than that of $638 \mathrm{~K}$. Higher ambient temperature leads to the generation of more $n-b u t a n o l$ vapor inside the droplet. The high speed of bubble expansion caused by more n-butanol vapor makes the droplet breakup easily, leading to the high frequency of fluctuation and low $\left(\mathrm{D}_{\max } / \mathrm{D}_{0}\right)^{2}$ at $738 \mathrm{~K}$.

(2). Three turning points can be found in the curve of transient temperature growth rate at 638 and $738 \mathrm{~K}$. The first turning 
point is around the time of $\left(\mathrm{D}_{\max } / \mathrm{D}_{0}\right)^{2}$. The second and third turning points are at the start and end of equilibrium evaporation phase.

(3). Four characteristic droplet temperatures are defined in this work, including the droplet temperatures at the start $\left(\mathrm{T}_{1}\right)$ and end $\left(T_{2}\right)$ of the transient heating phase, at the time of $\left(\mathrm{D}_{\max } / \mathrm{D}_{0}\right)^{2}\left(\mathrm{~T}_{3}\right)$ and at the end of total lifetime $\left(\mathrm{T}_{4}\right)$. All $\mathrm{T}_{1}$ values are around $354 \mathrm{~K}$ and approximately unchanged. All $\mathrm{T}_{2}$ values are around $386 \mathrm{~K}$ and slightly lower than the boiling point of $\mathrm{n}$-butanol (390 $\mathrm{K})$. All $\mathrm{T}_{3}$ values are around $403 \mathrm{~K}$ and slightly higher than the boiling point of n-butanol $(390 \mathrm{~K})$. All $\mathrm{T}_{4}$ values are around $540 \mathrm{~K}$ and slightly lower than the boiling point of n-hexadecane $(560 \mathrm{~K})$.

(4). Three characteristic durations are defined in this work, including the durations of transient heating phase $\left(\mathrm{t}_{\mathrm{TH}}\right)$, fluctuation evaporation phase $\left(t_{\mathrm{FE}}\right)$ and total lifetime of droplet evaporation $\left(\mathrm{t}_{\mathrm{TL}}\right)$. All the three characteristic durations decrease with the increase of ambient temperature. The percentages of $t_{\mathrm{TH}} / t_{\mathrm{TL}}$ and $\mathrm{t}_{\mathrm{FE}} / \mathrm{t}_{\mathrm{TL}}$ are stable with increasing ambient temperature (around $12.71 \%$ and $52.23 \%$ respectively). Higher ambient temperature leads to shorter $\mathrm{t}_{\mathrm{TH}}$ because of higher temperature growth rate in the transient heating phase. The contribution of $\mathrm{t}_{\mathrm{FE}}$ to the reduction of $\mathrm{t}_{\mathrm{TL}}$ is $44.23 \%$ from 638 to $688 \mathrm{~K}$ and it is $82.86 \%$ from 688 to $738 \mathrm{~K}$. The reduction of $\mathrm{t}_{\mathrm{FE}}$ plays an important role in the decrease of $\mathrm{t}_{\mathrm{TL}}$.

\section{Acknowledgement}

This work was supported by the Graduate's Innovation Fund of Huazhong University of Science and Technology (No. 5003120004).

\section{References:}

[1]. Liu H, Wang X, Zheng Z, Gu J, Wang H, Yao M. Experimental and simulation investigation of the combustion characteristics and emissions using n-butanol/biodiesel dual-fuel injection on a diesel engine. Energy 2014;74:741-52.

[2]. Chen Z, Wu Z, Liu J, Lee C. Combustion and emissions characteristics of high n-butanol/diesel ratio blend in a heavy-duty diesel engine and EGR impact. Energ Convers Manage 2014;78:787-95. 
[3]. Chang Y, Lee $\mathrm{W}, \mathrm{Wu} \mathrm{TS}, \mathrm{Wu} \mathrm{C}$, Chen S. Use of water containing acetone - butanol - ethanol for NOx-PM (nitrogen oxide-particulate matter) trade-off in the diesel engine fueled with biodiesel. Energy 2014;64:678-87.

[4]. Lee W, Liu Y, Mwangi FK, Chen W, Lin S, Fukushima Y. Assessment of energy performance and air pollutant emissions in a diesel engine generator fueled with water-containing ethanol - biodiesel - diesel blend of fuels. Energy 2011;36:5591-99.

[5]. Jani DB, Mishra M, Sahoo PK. Performance studies of hybrid solid desiccant - vapor compression air-conditioning system for hot and humid climates. Energ Buildings 2015;102:284-92.

[6]. Jani DB, Mishra M, Sahoo PK. Solid desiccant air conditioning - a state of the art review. Renewable and Sustainable Energy Reviews 2016;60:1451-69.

[7]. Hoxie A, Schoo R, Braden J. Microexplosive combustion behavior of blended soybean oil and butanol droplets. Fuel $2014 ; 120: 22-29$.

[8]. Coughlin B, Hoxie A. Combustion characteristics of ternary fuel Blends: Pentanol, butanol and vegetable oil. Fuel 2017;196:488-96.

[9]. Rakopoulos DC, Rakopoulos CD, Giakoumis EG, Papagiannakis RG, Kyritsis DC. Influence of properties of various common bio-fuels on the combustion and emission characteristics of high-speed DI (direct injection) diesel engine: Vegetable oil, bio-diesel, ethanol, n-butanol, diethyl ether. Energy 2014;73:354-66.

[10]. Han K, Yang B, Zhao C, Fu G, Ma X, Song G. Experimental study on evaporation characteristics of ethanol - diesel blend fuel droplet. Exp Therm Fluid Sci 2016;70:381-88.

[11]. Wu H, Nithyanandan K, Zhang J, Lin Y, Lee TH, Lee CF. Impacts of Acetone - Butanol - Ethanol (ABE) ratio on spray and combustion characteristics of ABE - diesel blends. Appl Energ 2015;149:367-78.

[12]. Botero ML, Huang Y, Zhu DL, Molina A, Law CK. Synergistic combustion of droplets of ethanol, diesel and biodiesel mixtures. Fuel 2012;94:342-47.

[13]. Han K, Zhao C, Fu G, Zhang F, Pang S, Li Y. Evaporation characteristics of dual component droplet of benzyl azides-hexadecane mixtures at elevated temperatures. Fuel 2015;157:270-78. 
[14]. Nomura H, Ujiie Y, Rath HJ, Sato J, Kono M. Experimental study on high-pressure droplet evaporation using microgravity conditions. Symposium (International) on Combustion 1996;26:1267-73.

[15]. Ma X, Zhang F, Han K, Yang B, Song G. Evaporation characteristics of acetone - butanol - ethanol and diesel blends droplets at high ambient temperatures. Fuel 2015;160:43-49.

[16]. Zhu M, Zhang Z, Zhang Y, Liu P, Zhang D. An experimental investigation into the ignition and combustion characteristics of single droplets of biochar water slurry fuels in air. Appl Energ 2017;185:2160-67.

[17]. Setyawan HY, Zhu M, Zhang Z, Zhang D. Ignition and combustion characteristics of single droplets of a crude glycerol in comparison with pure glycerol, petroleum diesel, biodiesel and ethanol. Energy 2016;113:153-59.

[18]. Zhu M, Ma Y, Zhang Z, Chan YL, Zhang D. Effect of oxygenates addition on the flame characteristics and soot formation during combustion of single droplets of a petroleum diesel in air. Fuel 2015;150:88-95.

[19]. Zhu M, Ma Y, Zhang D. Effect of a homogeneous combustion catalyst on combustion characteristics of single droplets of diesel and biodiesel. P Combust Inst 2013;34:1537-44.

[20]. Javed I, Baek SW, Waheed K, Ali G, Cho SO. Evaporation characteristics of kerosene droplets with dilute concentrations of ligand-protected aluminum nanoparticles at elevated temperatures. Combust Flame 2013;160:2955-63.

[21]. Javed I, Baek SW, Waheed K. Evaporation characteristics of heptane droplets with the addition of aluminum nanoparticles at elevated temperatures. Combust Flame 2013;160:170-83.

[22]. Hashimoto N, Nomura H, Suzuki M, Matsumoto T, Nishida H, Ozawa Y. Evaporation characteristics of a palm methyl ester droplet at high ambient temperatures. Fuel 2015;143:202-10.

[23]. Chen G, Li Y, Lan C, Lin H, Chao Y. Micro-explosion and burning characteristics of a single droplet of pyrolytic oil from castor seeds. Appl Therm Eng 2017;114:1053-63.

[24]. Hou S, Rizal FM, Lin T, Yang T, Wan H. Microexplosion and ignition of droplets of fuel oil/bio-oil (derived from lauan wood) blends. Fuel 2013;113:31-42.

[25]. Watanabe H, Suzuki Y, Harada T, Matsushita Y, Aoki H, Miura T. An experimental investigation of the breakup characteristics of secondary atomization of emulsified fuel droplet. Energy 2010;35:806-13. 
[26]. Javed I, Baek SW, Waheed K. Autoignition and combustion characteristics of kerosene droplets with dilute concentrations of aluminum nanoparticles at elevated temperatures. Combust Flame 2014;162:774-87.

[27]. Javed I, Baek SW, Waheed K. Autoignition and combustion characteristics of heptane droplets with the addition of aluminium nanoparticles at elevated temperatures. Combust Flame 2014;162:191-206.

[28]. Reid RC, Prausnitz JM, Poling BE. The properties of gases and liquids. New York: The McGraw-Hill Companies; 2004.

[29]. Jin C, Yao M, Liu H, Lee CF, Ji J. Progress in the production and application of n-butanol as a biofuel. Renewable and Sustainable Energy Reviews 2011;15:4080-106.

[30]. Ghassemi H, Baek SW, Khan QS. Experimental study on binary droplet evaporation at elevated pressures and temperatures. Combust Sci Technol 2006;178:1031-53.

[31]. Ghassemi H, Baek SW, Khan QS. Experimental study on evaporation of kerosene droplets at elevated pressures and temperatures. Combust Sci Technol 2006;178:1669-84.

[32]. Nomura H, Murakoshi T, Suganuma Y, Ujiie Y, Hashimoto N, Nishida H. Microgravity experiments of fuel droplet evaporation in sub- and supercritical environments. P Combust Inst 2017;36:2425-32.

[33]. Zhang Y, Huang R, Wang Z, Xu S, Huang S, Ma Y. Experimental study on puffing characteristics of biodiesel-butanol droplet. Fuel 2017;191:454-62.

[34]. Zhang Y, Huang R, Xu S, Huang Y, Huang S, Ma Y. The effect of different n-butanol-fatty acid methyl esters (FAME) blends on puffing characteristics. Fuel 2017;208:30-40.

[35]. Zeng Y, Lee CF. An atomization model for flash boiling sprays. Combust Sci Technol 2001;169:45-67.

[36]. Zeng Y, Lee CF. Modeling droplet breakup processes under micro-explosion conditions. P Combust Inst 2007;31:2185-93.

[37]. Shawn D G, Abraham J. Supercritical droplet vaporization and combustion studies. Prog Energ Combust 1996;22:1-28.

[38]. Moffat RJ. Describing the uncertainties in experimental results. Exp Therm Fluid Sci 1988;1:3-17. 